\title{
Preparation and stability of silicone dioxide dispersed in polyalkylene glycol based nanolubricants
}

\author{
M.Z. Sharif ${ }^{1, *}$, W.H. Azmi ${ }^{1,2}$, A.A.M. Redhwan ${ }^{1,3}$, N.M.M. Zawawi ${ }^{1}$ \\ ${ }^{1}$ Automotive Engineering Research Group (AERG), Faculty of Mechanical Engineering, Universiti \\ Malaysia Pahang (UMP), 26600 Pekan, Pahang, Malaysia, \\ ${ }^{2}$ Automotive Engineering Centre, Universiti Malaysia Pahang (UMP), 26600 Pekan, Pahang, \\ Malaysia. \\ ${ }^{3}$ Faculty Manufacturing Engineering Technology, TATI Universiti College (TATIUC), 24000 \\ Kemaman, Terengganu, Malaysia.
}

\begin{abstract}
Nanolubricant is one of the efforts introduced by researchers to increase efficiency in many mechanical application, especially in refrigeration. Two-step method is the most common method used in the process of adding nanoparticles dispersed in base lubricant because of the simplicity of the process to prepare a stable solution. In this work, the $\mathrm{SiO}_{2} / \mathrm{PAG}$ nanolubricants were prepared using two-steps method without the use of surfactant. The stability of $\mathrm{SiO}_{2} / \mathrm{PAG}$ nanolubricant was observed trough sedimentation photograph capturing technique and UVVis spectrophotometric test. The results shown that there are minimum sedimentation observed over one month. This result also confirmed via the $\mathrm{UV}-\mathrm{Vis}$ test; the nanolubricant relative concentration was maintained at over $70 \%$ compared to the initial concentration.
\end{abstract}

\section{Introduction}

Different lubricants with various properties are created nowadays to be utilized in many types of application involving mechanical parts, especially in refrigeration compressor. In a mechanical system, friction is a primary cause for energy loss. Hence, lubricant is the best solution to reduce friction consequently decreasing energy losses and heat production [1]. Thus, to improve the energy-efficiency systems involving mechanical system, it is important to enhance the lubricant properties. Application of nanotechnology dispersed in lubricant is a new way to improve the lubricating properties and interested many scholars to explore further in this area. For example, the researcher has proven that $\mathrm{SiO}_{2}$ not only have the advantages of better heat transfer effect, but also give improvement to the tribulogical properties due to reduce friction coefficient and better anti wear properties [2].

The nanotechnology utilization as property's enhancement effectiveness in numerous applications, such as, motor and transmission oil cooling, refrigeration (domestic and chillers), evaporator fumes warming and cooling of buildings; cooling of electronics

\footnotetext{
*Corresponding author: sharif5865@yahoo.com
} 
component, oils, biomedical application and nanofluids in transformer oil has been studied by the different researchers [3-5]. According to Alawi et al. [6], there are few advantages of applying nanoparticles as additives in a lubricant for application in refrigerant. The advantage is by enhancing the lubricant-refrigerant solubility and also significantly increases the thermo-physical properties of lubricant. It is also improves the wear rate and friction coefficient. Currently, there are two available methods for preparing the nanolubricant which is a one-step method and two-step method. Two-step method is the most common method used in producing nanolubricant because of the simplicity of the process in order to prepare the stable solution. However, this method has a drawback on agglomeration due to large and active in surface area [7]. Hence, a suitable method for stabilize the solution is required by adding $\mathrm{pH}$ and obtaining an optimum ultrasonic sonification time. Previously, the effect of sonification time on stability was being done [8]. The sonification time may vary according to the types of base fluid.

Therefore, the purpose of this paper is to establish the preparation of the $\mathrm{SiO}_{2}$ dispersed in Polyalkylene Glycol nanolubricant. Then, the study on stability of the nanolubricant evaluated using visual analysis and UV-Vis Spectrometer absorbance analysis.

\section{Materials}

Nanoparticles of $\mathrm{SiO}_{2}$ are obtained from Sigma-Aldrich Corporation. The $\mathrm{SiO}_{2}$ nanoparticle average sizes are $30 \mathrm{~nm}$ and displayed in Fig. 1. The properties of the nanoparticles are shown in Table 1.

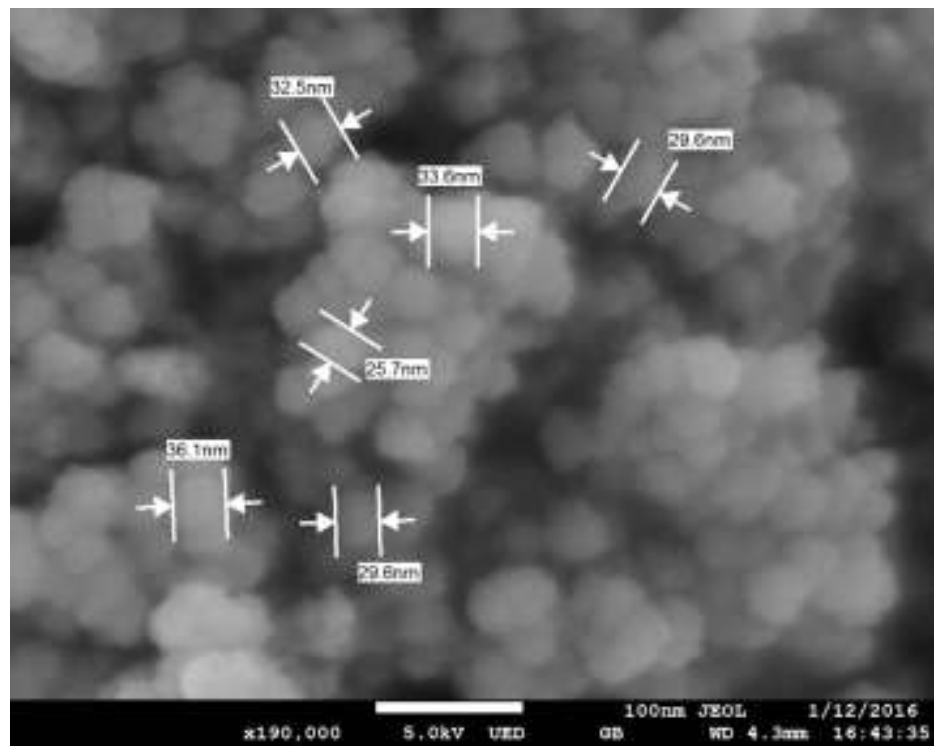

Fig. 1. $\mathrm{SiO}_{2}$ nanoparticles with average size of $30 \mathrm{~nm}$.

Polyalkylene Glycol (PAG) lubricant, is specially designed to be used in compressor for air conditioning in automobiles and lorry obtained from Denso. The properties of the PAG lubricant are shown in Table 2. 
Table 1. Properties of $\mathrm{SiO}_{2}$ nanoparticles used in this experiment $[9,10]$.

\begin{tabular}{|c|c|}
\hline Property & $\mathbf{S i O}_{2}$ \\
\hline Molecular mass, $\mathrm{g} \mathrm{mol}^{-1}$ & 60.08 \\
\hline Average Particle diameter, $\mathrm{nm}$ & 30 \\
\hline Density, $\mathrm{kg} \mathrm{m}^{-3}$ & 2220 \\
\hline Thermal Conductivity, $\mathrm{W} \mathrm{m}^{-1} \mathrm{k}^{-1}$ & 1.4 \\
\hline Specific heat, $\mathrm{J} \mathrm{kg}^{-1} \mathrm{~K}^{-1}$ & 745 \\
\hline
\end{tabular}

Table 2. Properties of PAG lubricant [11, 12].

\begin{tabular}{|c|c|}
\hline Specifications & Value \\
\hline Kinematic viscosity, cSt @ $40{ }^{\circ} \mathrm{C}$ & $41.4-50$ \\
\hline Kinematic viscosity, cSt @ $100{ }^{\circ} \mathrm{C}$ & 11 \\
\hline Density, kg/cm ${ }^{3} @ 15^{\circ} \mathrm{C}$ & 0.9954 \\
\hline Viscosity index & 184 \\
\hline Pour point, ${ }^{\circ} \mathrm{C}$ & -51 \\
\hline
\end{tabular}

\section{Methodology}

\subsection{Preparation of nanolubricant}

Nanolubricant of $\mathrm{SiO}_{2}$ nanoparticles dispersed in Polyalkylene Glycol (PAG) lubricant was prepared using two-step methods.In order to prepare the nanolubricant, proper mixing and the stabilization of the particles are required. In the present study, $\mathrm{SiO}_{2}$ nanoparticles will mix with PAG lubricant using a magnetic stirrer for 1 hour, and then dispersed continuously using ultrasonic bath vibrator Fisherbrand (model: FB15051) generating ultrasonic pulses of $230 \mathrm{~V}$ at $50 \pm 3 \mathrm{kHz}$ for 2 hour. The 2 hour sonification time was determined using UV-Vis spectrophotometer analysis as an optimum time for the sonification to ensure that the nanoparticles are mixed well with less sedimentation potential and better mean particle size. The detailed results will be explained in the next sub-chapter 4.1.The sonicator will break down the agglomeration and ensure the nanoparticle well dispersed into the base solution. The detailed step of preparation was shown by Azmi et al.[13]. The volume concentrations between 0.2 to $1.0 \%$ of nanolubricant was prepared in this experiment. The nanolubricant volume concentration was calculated using the formula in Eq. (1).

$$
\phi=\frac{\frac{m_{p}}{\rho_{p}}}{\frac{m_{p}}{\rho_{p}}+\frac{m_{L}}{\rho_{L}}} \times 100
$$

\subsection{Stability evaluation of the nanolubricant}

Stability of nanolubricant can be determined in different ways. It this experiment, the relative stability of nanosupension was observed using sedimentation photograph capturing methods and UV- Vis Spectrophotometer analysis method. Therefore, the rate of sedimentation will be identified by analyzing the data. The visual sedimentation photograph method was the main method to find out the visual sedimentation of nanolubricant [14]. The 
sample was observed for a month, and the image of nano suspension sedimentation apparentness will be compared.Another method for stability is using UV-Vis Spectrophotometer (model: Genesys 10). The UV-Vis can measure the colloidal stability of the dispersions of nanolubricant. The picture of the instrument was shown in Fig.2.

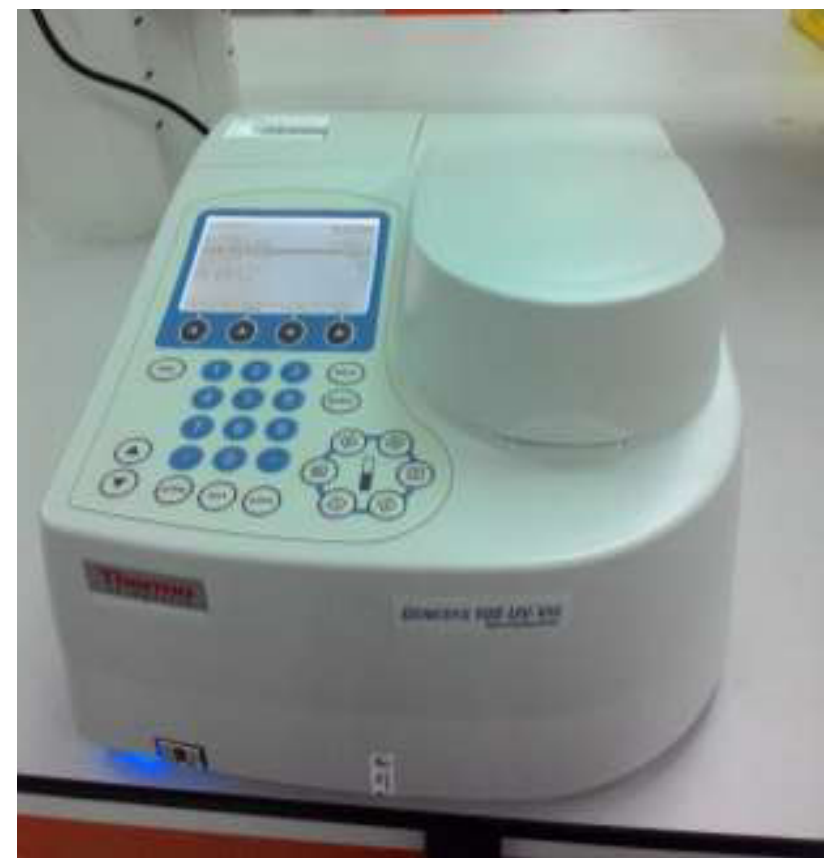

Fig. 2. Genesys $10 \mathrm{UV}-\mathrm{V}$ is Spectrometer.

UV-vis spectrophotometer measures the absorption and the scattering of light by comparing the intensity of the light of the nanolubricant with the reference, the base lubricant [14]. In addition, the absorption and dispersions in the nanolubricant or nanofluid generally measured in the range of 200-900 nm wavelength [15]. Normally, nanosuspension stability is analyzed by measuring the sediment volume and absorbance versus the sediment time [16]. The absorbance for three volume concentration will be observed in this experiment for over a month.

\section{Results and discussion}

\subsection{Sedimentation photograph capturing methods}

$\mathrm{SiO}_{2}$ nanoparticles were added to $\mathrm{PAG}$ lubricant used in the refrigeration system. The samples were left within a month. Sample pictures were taken for each hour, day, and week to see the sedimentation and deposition of the nanoparticle in the liquid.The images of the nanoparticle suspension sedimentation were compared. Fig.3 shows the sedimentation photograph of $\mathrm{SiO}_{2} / \mathrm{PAG}$ nanolubricant after preparation and a month of preparation. In the figures., it can be seen that the sedimentation was minimum even after a month. There is not much change in terms of color form observed the experiment even after a month of preparation. Furthermore, only a small layer of two-layer layer form signifying that fewer sedimentation occurred in that particular liquid. 


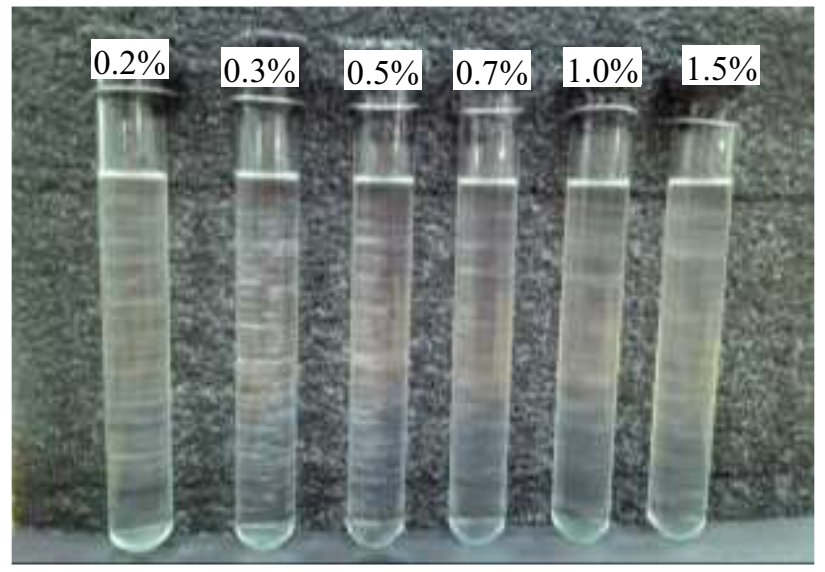

(a) Visual sedimentation after preparation

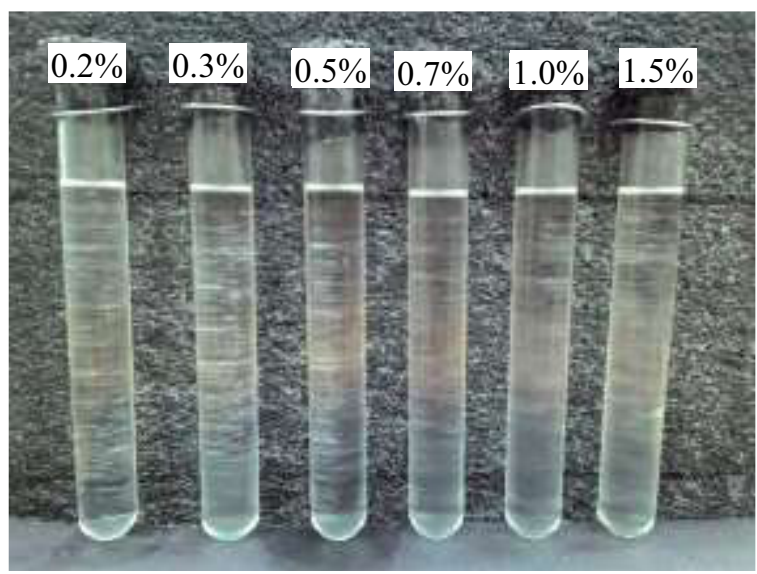

(b) Visual sedimentation after one month

Fig. 3. $\mathrm{SiO}_{2} / \mathrm{PAG}$ nanolubricant sedimentation photograph.

\subsection{UV-vis spectrophotometer analysis methods}

After the preparation, the particle morphology was observed for different concentrations. Fig. 4 shows the UV-Vis spectra of $\mathrm{SiO}_{2}$ with their respective concentrations. The absorbance of all nanolubricants demonstrates the characteristic absorption in the range of 200 to $400 \mathrm{~nm}$ wavelengths. Besides, the absorbance of nanolubricant increases from lower concentration to higher concentration. From the observation, it can be concluded that lower concentration of nanolubricant have more potential for agglomeration and faster sedimentation time.In the UV-vis spectrometer sedimentation test, firstly, the peak absorbance wavelength of the $\mathrm{SiO}_{2} / \mathrm{PAG}$ nanolubricant at dilute concentration, which is $1.5 \%$ was tested. Fig. 5 shows the result of the scanning of the UV-vis spectrometer in the range of $200 \mathrm{~nm}$ to $400 \mathrm{~nm}$. The scanning results show that the peak absorbance for $\mathrm{SiO}_{2} / \mathrm{PAG}$ lies at $317 \mathrm{~nm}$ wavelength. 


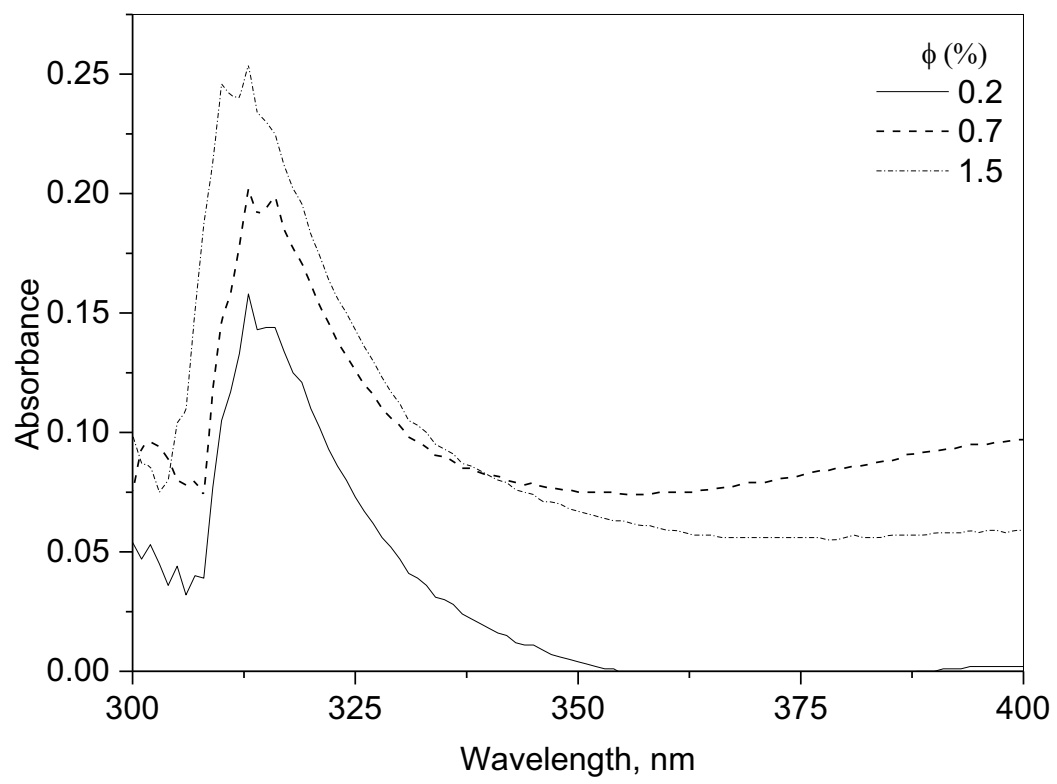

Fig. 4. UV-Vis spectrometer of different concentrations.

The UV-Vis spectrometer analysis was also done to confirm what is the best time needed for the sonification time to obtain great stability. The same concentration of $\mathrm{SiO}_{2} / \mathrm{PAG}$ nanolubricant was prepared for different duration of sonification process time to achieve this purpose. The absorbance ratio over sedimentation time in hours for five samples graph was shown in Fig. 6. The data plotted in Fig. 6 clearly show that the absorbance ratio is decreasing with sedimentation time and strongly dependent to sonication time. Finally, the best or optimum sonication time for $\mathrm{SiO}_{2} / \mathrm{PAG}$ nanolubricant is attained at 2.0 hours' sonication time. The sample remained stable during the sedimentation time and absorbance ratio was above approximately $80 \%$ even after 336 hours (two weeks).

After that, the relative stability measurement will be done on three concentrations of nanolubricant $(0.5 \%, 1.0 \%$, and $1.5 \%$ volume concentration) for one month. The nanolubricants was prepared using the optimum time for sonification process which is 2 hours. The supernatant particle absorbance for three concentrations against the sedimentation graph was shown in Fig.7.

From the graph and the visual sedimentation photograph result, it has clearly shown that $\mathrm{SiO}_{2} / \mathrm{PAG}$ nanolubricant was stable. After a month, the absorbance was maintained within the range of 0.24 to 0.35 values, showing that the relative concentration of these nanolubricant was maintained at over $70 \%$ compared to the initial concentration. 


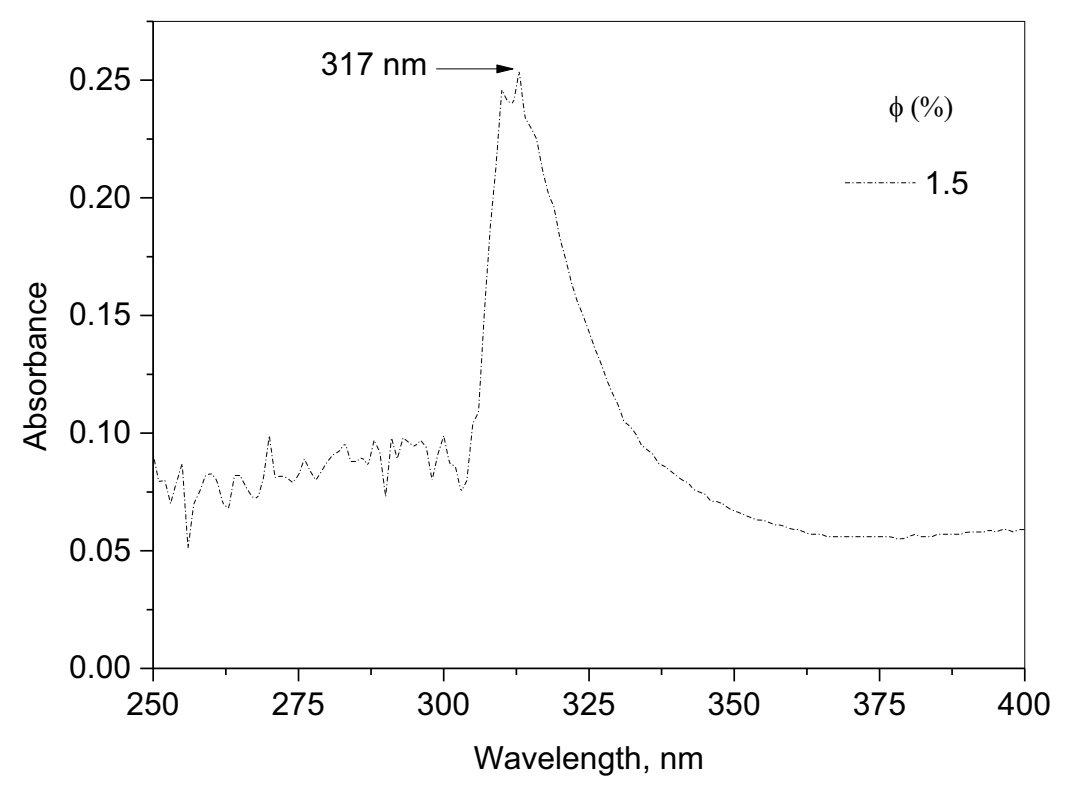

Fig. 5. UV-Vis spectrometer scanning graph at $200 \mathrm{~nm}$ to $400 \mathrm{~nm}$.

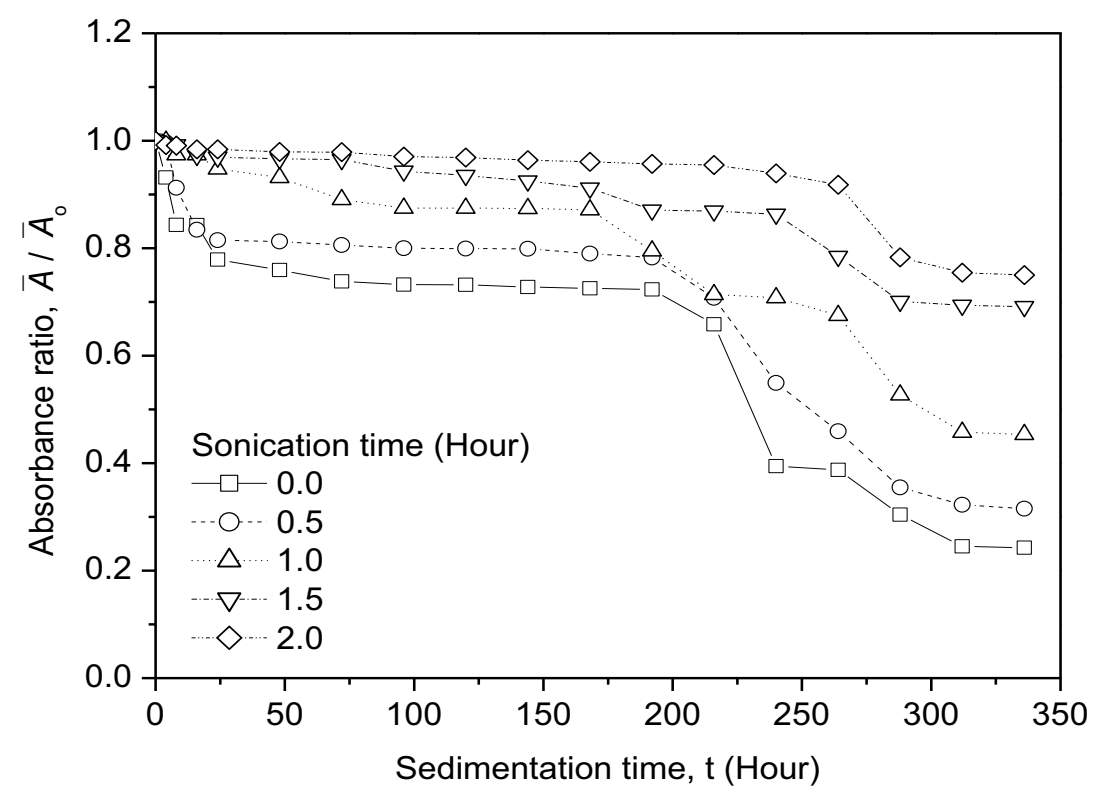

Fig. 6. Absorbance ratio of $\mathrm{SiO}_{2} / \mathrm{PAG}$ nanolubricant as a function of sedimentation time. 


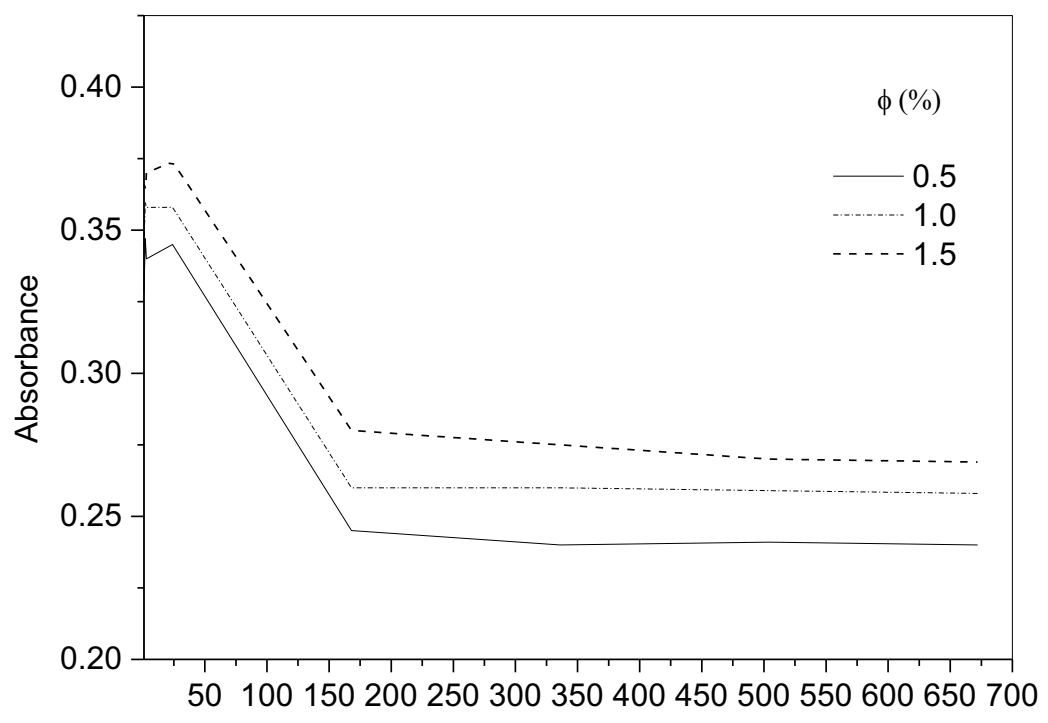

Sedimentation hours $(\mathrm{h})$

Fig. 7. UV-Vis spectrometer scanning graph at $200 \mathrm{~nm}$ to $400 \mathrm{~nm}$.

\section{Conclusions}

$\mathrm{SiO}_{2}$ was dispersed into the PAG lubricant which normally utilize in the refrigeration system using two-steps method without any surface stabilizer or surfactants. The best or optimum sonication time for $\mathrm{SiO}_{2} / \mathrm{PAG}$ nanolubricant is attained at 2.0 hours' sonication process duration which was confirmed by using the UV-Vis spectrophotometer analysis. The stability properties of $\mathrm{SiO}_{2} / \mathrm{PAG}$ nanolubricant were evaluated at few concentrations by visual sedimentation photograph and $\mathrm{UV}-\mathrm{Vis}$ spectrophotometer method. From the sedimentation photograph, it can be seen that the sedimentation was minimum even after a month. There are no apparent changes on the samples after one month signifying that fewer sedimentation occurred in that particular liquid In the UV-Vis spectrometer test, it was shown that the peak absorbance of the $\mathrm{SiO}_{2} / \mathrm{PAG}$ nanolubricant lies at $317 \mathrm{~nm}$ wavelengths. After one month, the result from the UV-Vis showing that the relative concentration of these nanolubricant was maintained at over $70 \%$ compared to the initial concentration. It can be concluded from the graph and the visual sedimentation photograph result; it has clearly shown that $\mathrm{SiO}_{2} / \mathrm{PAG}$ nanolubricant was in a stable condition over a month of observation.

The authors are grateful to the Universiti Malaysia Pahang (UMP) and the Automotive Engineering Centre (AEC) for financial supports given under RDU1403153 and RDU151411 (RAGS/1/2015/TK0/UMP/03/2).

\section{References}

1. C. R. Ferguson and A. T. Kirkpatrick, Internal combustion engines: applied thermosciences: John Wiley \& Sons, (2015).

2. X. Li, Z. Cao, Z. Zhang, and H. Dang, "Surface-modification in situ of nano- $\mathrm{SiO}_{2}$ and its structure and tribological properties," Applied Surface Science, vol. 252, pp. 78567861, (2006). 
3. J. Eastman, U. Choi, S. Li, L. Thompson, and S. Lee, "Enhanced thermal conductivity through the development of nanofluids," in MRS proceedings, p. 3,(1996).

4. E. Serrano, G. Rus, and J. Garcia-Martinez, "Nanotechnology for sustainable energy," Renewable and Sustainable Energy Reviews, vol. 13, pp. 2373-2384, (2009).

5. R. Saidur, K. Leong, and H. Mohammad, "A review on applications and challenges of nanofluids," Renewable and Sustainable Energy Reviews, vol. 15, pp. 1646-1668, (2011).

6. O. A. Alawi, N. A. C. Sidik, and H. Mohammed, "A comprehensive review of fundamentals, preparation and applications of nanorefrigerants," International Communications in Heat and Mass Transfer, vol. 54, pp. 81-95, (2014).

7. M. Drzazga, M. Lemanowicz, G. Dzido, and A. Gierczycki, "Preparation of metal oxide-water nanofluids by two-step method," Inż. Ap. Chem, vol. 51, pp. 213-215, (2012).

8. S. J. Chung, J. P. Leonard, I. Nettleship, J.-K. Lee, Y. Soong, D. V. Martello, et al., "Characterization of $\mathrm{ZnO}$ nanoparticle suspension in water: effectiveness of ultrasonic dispersion," Powder Technology, vol. 194, pp. 75-80, (2009).

9. B. C. Pak and Y. I. Cho, "Hydrodynamic and heat transfer study of dispersed fluids with submicron metallic oxide particles," Experimental Heat Transfer an International Journal, vol. 11, pp. 151-170, (1998).

10. R. S. Vajjha, D. K. Das, and D. P. Kulkarni, "Development of new correlations for convective heat transfer and friction factor in turbulent regime for nanofluids," International Journal of Heat and Mass Transfer, vol. 53, pp. 4607-4618, (2010).

11. W. L. Brown, "Polyalkylene glycols," CRC Handbook of Lubrication and Tribology, vol. 3, pp. 253-267, (1993).

12. Dow, "Material Safety Data Sheet," Ucon Refrigerant Lubricant 213, (2013).

13. W. H. Azmi, K. Sharma, P. Sarma, R. Mamat, S. Anuar, and V. D. Rao, "Experimental determination of turbulent forced convection heat transfer and friction factor with $\mathrm{SiO}_{2}$ nanofluid," Experimental Thermal and Fluid Science, vol. 51, pp. 103-111, (2013).

14. A. Ghadimi, R. Saidur, and H. Metselaar, "A review of nanofluid stability properties and characterization in stationary conditions," International Journal of Heat and Mass Transfer, vol. 54, pp. 4051-4068, (2011).

15. K. Lee, Y. Hwang, S. Cheong, L. Kwon, S. Kim, and J. Lee, "Performance evaluation of nano-lubricants of fullerene nanoparticles in refrigeration mineral oil," Current Applied Physics, vol. 9, pp. e128-e131, (2009).

16. Y. Hwang, J.-K. Lee, J.-K. Lee, Y.-M. Jeong, S.-i. Cheong, Y.-C. Ahn, et al., "Production and dispersion stability of nanoparticles in nanofluids," Powder Technology, vol. 186, pp. 145-153, (2008). 